\title{
Preparation of arginine-glycine-aspartic acid-
} modified biopolymeric nanoparticles containing epigalloccatechin-3-gallate for targeting vascular endothelial cells to inhibit corneal neovascularization

This article was published in the following Dove Press journal:

International Journal of Nanomedicine

30 December 2016

Number of times this article has been viewed

Che-Yi Chang, 1,2,* MingChen Wang, ${ }^{2, *}$ Takuya Miyagawa,' Zhi-Yu Chen,' Feng-Huei Lin, ${ }^{3,4}$ Ko-Hua Chen, ${ }^{5,6}$ Guei-Sheung Liu, ${ }^{7}$ Ching-Li Tseng'

'Graduate Institute of Biomedical Materials and Tissue Engineering, College of Biomedical Engineering, Taipei Medical University, Taipei, ${ }^{2}$ Department of Biomedical Engineering, Chung Yuan Christian University, Taoyuan, ${ }^{3}$ Institute of Biomedical Engineering and Nanomedicine, National Health Research Institutes, Zhunan, ${ }^{4}$ Institute of Biomedical Engineering, National Taiwan University, ${ }^{5}$ Department of Ophthalmology, Taipei Veterans General Hospital, ${ }^{6}$ Department of Ophthalmology, School of Medicine, College of Medicine, Taipei Medical University, Taipei, Taiwan; ${ }^{7}$ Centre for Eye Research Australia, University of Melbourne, Royal Victorian Eye and Ear Hospital, East Melbourne, VIC, Australia

*These authors contributed equally to this work

Correspondence: Ching-Li Tseng Graduate Institute of Biomedical Materials and Tissue Engineering, College of Biomedical Engineering, Taipei Medical University, 250, Wu-Hsing Street,

Taipei II0, Taiwan

Tel +886 22736 I66I ext 52I4

Fax +886227397059

Email chingli@tmu.edu.tw
Abstract: Neovascularization (NV) of the cornea can disrupt visual function, causing ocular diseases, including blindness. Therefore, treatment of corneal NV has a high public health impact. Epigalloccatechin-3-gallate (EGCG), presenting antiangiogenesis effects, was chosen as an inhibitor to treat human vascular endothelial cells for corneal NV treatment. An arginineglycine-aspartic acid (RGD) peptide-hyaluronic acid (HA)-conjugated complex coating on the gelatin/EGCG self-assembly nanoparticles (GEH-RGD NPs) was synthesized for targeting the $\alpha_{\mathrm{v}} \beta_{3}$ integrin on human umbilical vein endothelial cells (HUVECs) in this study, and a corneal NV mouse model was used to evaluate the therapeutic effect of this nanomedicine used as eyedrops. HA-RGD conjugation via $\mathrm{COOH}$ and amine groups was confirmed by ${ }^{1} \mathrm{H}$-nuclear magnetic resonance and Fourier-transform infrared spectroscopy. The average diameter of GEH-RGD NPs was $168.87 \pm 22.5 \mathrm{~nm}$ with positive charge (19.7 $\pm 2 \mathrm{mV}$ ), with an EGCG-loading efficiency up to $95 \%$. Images of GEH-RGD NPs acquired from transmission electron microscopy showed a spherical shape and shell structure of about $200 \mathrm{~nm}$. A slow-release pattern was observed in the nanoformulation at about $30 \%$ after 30 hours. Surface plasmon resonance confirmed that GEH-RGD NPs specifically bound to the integrin $\alpha_{v} \beta_{3}$. In vitro cell-viability assay showed that GEH-RGD efficiently inhibited HUVEC proliferation at low EGCG concentrations $(20 \mu \mathrm{g} / \mathrm{mL})$ when compared with EGCG or non-RGD-modified NPs. Furthermore, GEH-RGD NPs significantly inhibited HUVEC migration down to $58 \%$, lasting for 24 hours. In the corneal NV mouse model, fewer and thinner vessels were observed in the alkali-burned cornea after treatment with GEH-RGD NP eyedrops. Overall, this study indicates that GEH-RGD NPs were successfully developed and synthesized as an inhibitor of vascular endothelial cells with specific targeting capacity. Moreover, they can be used in eyedrops to inhibit angiogenesis in corneal NV mice. Keywords: RGD peptide, epigallocatechin gallate (EGCG), hyaluronic acid (HA), vascular endothelial cells, antiangiogenesis, corneal neovascularization

\section{Introduction}

Corneal neovascularization (NV), the formation of new vessels in the cornea, results from a variety of ocular diseases. Most of these pathologies are associated with hypoxia, inflammation, and/or limbic barrier function. ${ }^{1}$ In Taiwan, myopia is the most common eye disorder, diagnosed in $86 \%$ of the young population. ${ }^{2}$ Most subjects with myopia wear contact lenses, usually causing corneal hypoxia. In general, patients who sustain 
a traumatic eye injury (physical insult, infectious disease, or inflammation) are also at risk of developing corneal NV, which can have detrimental effects on the patient's vision. ${ }^{1}$ Corneal NV may eventually result in blindness. ${ }^{3}$ From these data, one can consider that a large population is at risk of developing corneal NV. Antiangiogenic therapy using VEGF antibody for treating corneal NV has been developed, and demonstrates great promise for treatment of this condition via subconjunctival or intraocular injection. ${ }^{4-6}$ However, an ideal therapeutic strategy, which improves outcomes in a less invasive manner, thereby reducing risk, and providing long-term inhibition of angiogenesis in a lesion-targeted manner, is urgently needed.

The main objective in ocular therapeutics is to provide and maintain an adequate concentration of the drug at the site of action. However, ocular drug delivery faces numerous obstacles that impede adequate drug delivery and efficacy. Ways to deliver drugs to different regions are topical eyedrops, intravitreal injections, and intraocular implants. ${ }^{7,8}$ Eyedrops represent a noninvasive approach, and most ocular diseases are treated with topical application of eyedrops. The major deficiencies of eyedrops include poor ocular drug bioavailability, nasolacrimal duct drainage, and poor penetration to the posterior segments of the eye. ${ }^{8}$ Because of these issues, suspension eyedrops are quickly cleared: $90 \%$ of the drug is cleared within 2 minutes, and only $5 \%$ of the administered dose permeates into the cornea. ${ }^{9}$ Nanotechnology has found a place in the medical field by providing new and more efficient ways to deliver treatment. Nanoparticles (NPs), especially biodegradable ones, have also found applications in ophthalmology, by providing safer, less invasive, cheaper treatment options, and by effectively increasing drug concentration in the eyes. ${ }^{8,10}$ The use of NPs to treat ocular diseases allows targeted delivery, controlled release, and enhanced pharmacokinetics, finally improving the therapeutic efficacy of drugs in the eye.

The major active component of green tea, (-)epigallocatechin-3-gallate (EGCG), has been studied as an antiangiogenesis agent. ${ }^{11,12}$ EGCG can inhibit angiogenesis by inhibiting the growth of endothelial cells and significantly reducing VEGF-induced corneal NV. ${ }^{13}$ Green tea can also inhibit inflammation and angiogenesis. ${ }^{14,15}$ Overall, EGCG could be a bifunctional antiangiogenic and anti-inflammatory agent for ocular NV treatment. During vascular remodeling and angiogenesis, several integrins are expressed on endothelial cells, and integrin $\alpha_{\mathrm{v}} \beta_{3}$ is involved in ocular angiogenesis. ${ }^{16}$ Synthetic arginine-glycine-aspartic acid (RGD) peptides can bind to $\alpha_{\mathrm{v}} \beta_{3}$ integrin to mediate cellular uptake and block $\alpha_{v} \beta_{3}$-integrin function to reduce blood flow in the vascular area. ${ }^{17}$ Therefore, RGD peptides have been chosen as targeting moieties that could be combined with NPs to treat vascular endothelial cells in the cornea NV.

In this study, we mixed gelatin biopolymer with EGCG (antiangiogenic agent) to form NPs, and performed surface decoration using hyaluronic acid (HA) with RGD-peptide conjugation, achieving specific targeting to vascular endothelial cells. Thereafter, this nanomedicine was used as eyedrops to evaluate its efficacy for corneal NV treatment in a mouse model.

\section{Materials and methods \\ Reagent and chemicals}

Gelatin type A (derived from porcine skin, bloom 110, bloom 300), EGCG ( $\geq 95 \%$ ), 1-ethyl-3-(3-dimethylaminopropyl) carbodiimide hydrochloride (EDC), $N$-hydroxysuccinimide (NHS), potassium persulfate $\left(\mathrm{K}_{2} \mathrm{~S}_{2} \mathrm{O}_{8}\right)$, sodium acetate (NaAc), 2,2'-azino-bis(3-ethylbenzothiazoline-6-sulfonic acid) diammonium salt (ABTS), $\mathrm{D}_{2} \mathrm{O}$, heparin, Cell Counting Kit (CCK)-8, and live/dead-cell double-staining kit were purchased from Sigma-Aldrich (St Louis, MO, USA). Sodium hyaluronate (1\%) was obtained from Maxigen Biotech Inc (Taipei, Taiwan). Human integrin $\alpha_{\mathrm{v}} \beta_{3}$ and a octyl- $\beta$ D-glucopyranoside formulation were bought from EMD Millipore (Billerica, MA, USA). Amicon Ultra-4 centrifugal filter unit and endothelial cell growth supplement (ECGS) were purchased from Merck Millipore (Billerica, MA, USA). H-Gly-Arg-Asp-Ser-Pro-Lys-OH (GRGDSPK) was purchased from MDBio Inc (Qingdao, China). Fluorescent dye (5-[and-6]-carboxytetramethylrhodamine, succinimidyl ester [TAMRA-SE]) mixed isomers and penicillin-streptomycinneomycin were acquired from Thermo Fisher Scientific (Waltham, MA, USA). A Vivaspin ${ }^{\mathrm{TM}} 500$ ultrafiltration device $(30 \mathrm{kDa})$ was purchased from Sartorius AG (Göttingen, Germany). Spectra/Por ${ }^{\circledR}$ membrane dialysis products (molecular weight 3,500) were obtained from Spectrum Laboratories Inc (Rancho Dominguez, CA, USA). Human umbilical vein endothelial cells (HUVECs) were purchased from the Bioresource Collection and Research Center (Hsinchu, Taiwan). Medium 199, phosphatebuffered saline (PBS), and $0.25 \%(\mathrm{w} / \mathrm{v})$ trypsin-1 $\mathrm{mM}$ ethylenediaminetetraacetic acid were purchased from Thermo Fisher Scientific. Fetal bovine serum (FBS) was obtained from GE Healthcare (Little Chalfont, UK). A topical anesthesia solution $\left(0.5 \%\right.$ Alcaine $\left.^{\circledR}\right)$ was bought from Alcon (Hünenberg, Switzerland). Grafco ${ }^{\circledR}$ silver nitrate applicators were purchased from Medline Industries Inc 
(Mundelein, IL, USA). All other reagent-grade chemicals were from Sigma-Aldrich.

\section{Preparation of gelatin-EGCG NPs with HA-RGD on their surface \\ Synthesis of RGD-HA conjugates}

Synthesis was performed according to a previously described protocol, with slight modifications. ${ }^{18}$ Two milliliters of HA $(5 \mathrm{mg} / \mathrm{mL})$ was added to $1 \mathrm{~mL}$ of EDC/NHS solution $(38 \mathrm{mg} / \mathrm{mL})$ and mixed at room temperature for 1 hour. GRGDSK peptide $(1 \mathrm{~mL})$ in $0.1 \mathrm{M} \mathrm{NaHCO}_{3}(10 \mathrm{mg} / \mathrm{mL})$ solution was then added for conjugation and kept at $4^{\circ} \mathrm{C}$ for 72 hours for further reaction under stirring. Nonreacting residues were removed by centrifugation using the Vivaspin ultrafiltration device, the solution was freeze-dried, and a white HA-RGD floccule was obtained. The reaction procedure is shown in Figure 1A. ${ }^{1} \mathrm{H}$-nuclear magnetic resonance (NMR) spectra were recorded in $\mathrm{D}_{2} \mathrm{O}$ at $25^{\circ} \mathrm{C}$ on a $500 \mathrm{MHz}$ NMR spectrometer (Avance DRX 500;

A

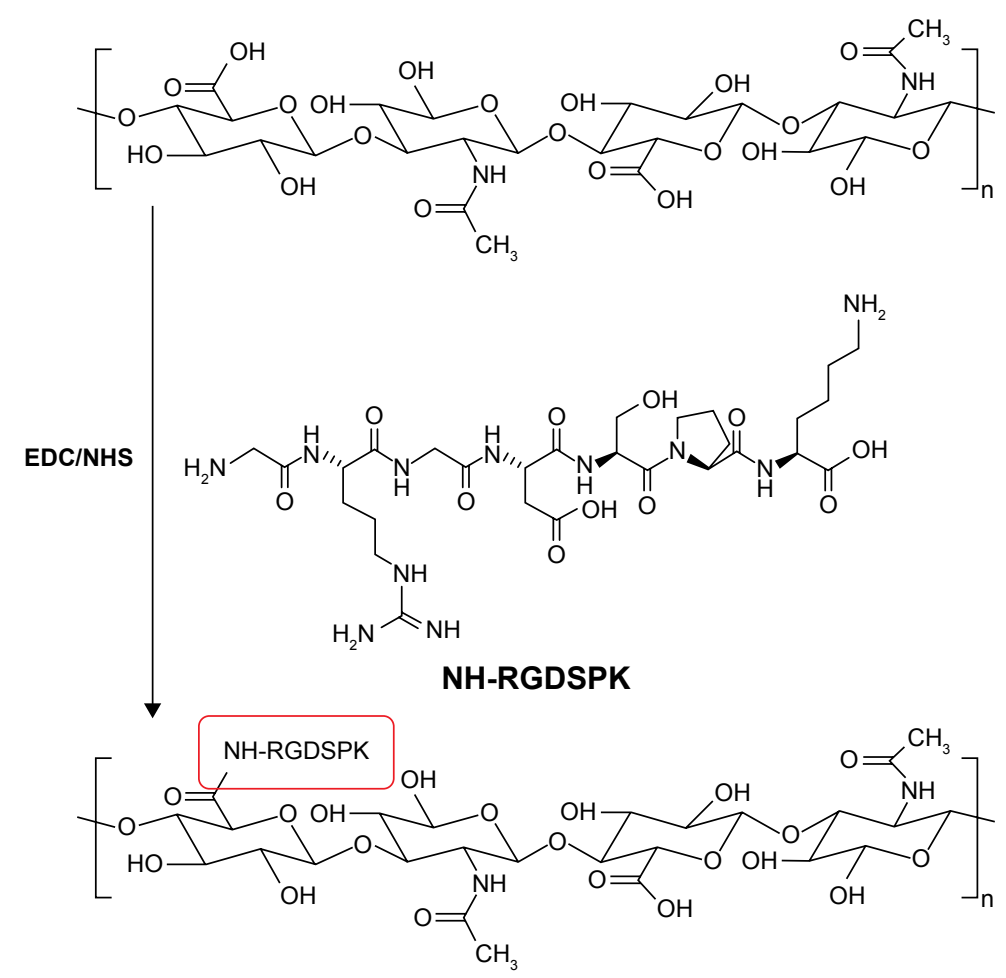

B

$\curvearrowright \overbrace + \underset{\text { Gelatin }}{+}+\mathrm{+}$

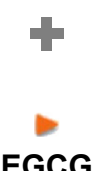

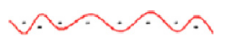

HA

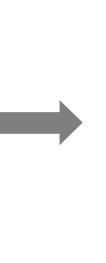

GE
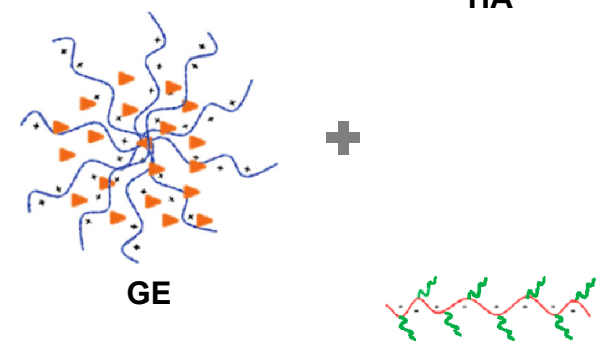

HA-GRGDSPK

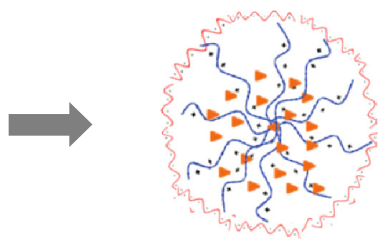

GEH

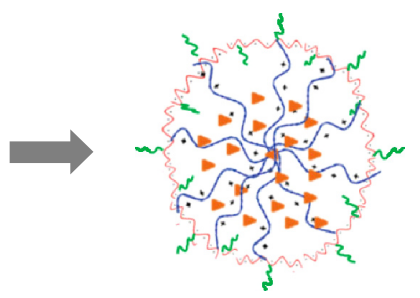

GEH-RGD

Figure I Schematic representations.

Notes: (A) HA-RGD peptide-conjugation reaction; (B) step for variant NP preparation with/without RGD modification. First, gelatin-EGCG self-assembling NPs were prepared (GE), followed by surface decoration with HA or HA-RGD (GEH and GEH-RGD, respectively).

Abbreviations: HA, hyaluronic acid; RGD, arginine-glycine-aspartic acid; NP, nanoparticle; EGCG, epigallocatechin-3-gallate; EDC, I-ethyl-3-(3-dimethylaminopropyl) carbodiimide hydrochloride; NHS, N-hydroxysuccinimide; GRGDSPK, H-Gly-Arg-Asp-Ser-Pro-Lys-OH. NH-RGDSPK, RGDSPK peptide conjugated with HA via amide bond formation. 
Bruker Corporation, Billerica, MA, USA), and the reaction via the carboxyl group was confirmed by Fourier-transform infrared spectroscopy (FT-IR; Jasco 4200; Jasco Inc, Easton, MD, USA). Pure HA and RGD powders were used to identify the appropriate wave numbers for analysis.

\section{Gelatin-EGCG NPs synthesized and HA-RGD coating on the surface}

Gelatin (type A, B110) and EGCG were the raw materials used for NP preparation. The synthesis was performed using a previously described process, with slight modifications. ${ }^{19}$ Equal volumes of gelatin and EGCG solution (both $0.44 \mathrm{w} / \mathrm{v} \%$ ) were mixed gently to form the self-assembly NPs under stirring, named GE thereafter. NPs were then prepared, and $100 \mu \mathrm{L}$ of HA or HA-RGD were separately added into the GE suspension (final HA concentration $0.25 \mathrm{w} / \mathrm{v} \%$ ). GE with HA coating on the surface is referred to as "GEH" hereafter and "GEH-RGD" is the abbreviation for GE with HA-RGD modifications on the surface. A schematic representation of the preparation process is shown in Figure 1B.

\section{Characterization of NPs}

\section{Size, charge, and morphology of NPs}

The particle size of NPs with/without RGD covering was determined by dynamic light scattering (DLS; ZS90 Plus; Malvern Instruments, Malvern, UK) at $25^{\circ} \mathrm{C}$ with scattering light at $90^{\circ} 180^{\prime \prime}$ for each measurement. These NP suspensions were diluted to ensure that the LS signal was within the sensitivity range. The $\zeta$-potential of the diluted suspension was measured using the automatic mode to confirm the surface charge of particles according to parameters of dielectric constant, refractive index, and viscosity of water. The structure/morphology of NPs was observed under transmission electron microscopy (TEM; HT-7700; Hitachi, Tokyo, Japan). The encapsulation efficiency of EGCG was determined by reacting with cation radicals of $\mathrm{ABTS}\left(\mathrm{ABTS}^{+} \bullet\right) .{ }^{20}$ In vitro drug-release measurements were then carried out: $1 \mathrm{mg} / \mathrm{mL}$ of concentrated NP suspension from $5 \mathrm{~mL}$ NPs with fluorescent dye conjugation (TAMRA) was placed in a dialysis membrane (Spectra/Por dialysis membrane), then soaked into $40 \mathrm{~mL}$ of PBS at $\mathrm{pH} 4$ and incubated in a shaker operated at $120 \mathrm{rpm}$ at $37^{\circ} \mathrm{C}$. For the free dye test, the same concentration of TAMRA was dissolved in water, then added to the dialysis bag for soaking in acidic PBS. At determined time intervals, $1 \mathrm{~mL}$ of PBS was removed and replaced by $1 \mathrm{~mL}$ of fresh PBS to maintain the total PBS volume. The amount of fluorescence released in the PBS solution was determined by a microplate reader, including fluorescence intensity (Varioskan Flash spectral scanning multimode reader; Thermo Fisher Scientific) under the fluorescence mode. The total amount of dye released was calculated as the accumulated release rate. The TAMRA-conjugation protocol is described as the following that $2 \mathrm{mg} / \mathrm{mL} \mathrm{NP}$ solution was suspended in $0.1 \mathrm{M}$ sodium bicarbonate buffer ( $\mathrm{pH} 4)$, then $50 \mu \mathrm{L}$ TAMRA dye was added to $0.5 \mathrm{~mL}$ NP solution. The conjugation reacted at room temperature for 1 hour. After that, unconjugated dye was removed by centrifugation with centrifugal filter device (molecular weight cutoff 10,000). The TAMRA concentration grafted on NPs was also quantified by a microplate reader, including fluorescence intensity (Thermo Fisher Scientific).

\section{RGD-modified NPs targeting $\alpha_{\mathrm{v}} \beta_{3}$ integrin}

The integrin $\alpha_{v} \beta_{3}$ is a well-known marker of angiogenic blood vessels. The binding ability of GRGDSPK peptide with integrin for guiding NPs to vascular vessels was determined by using the ProteOn ${ }^{\mathrm{TM}}$ XPR36 protein-interaction array system (Bio-Rad Laboratories, Hercules, CA, USA), which combines surface plasmon resonance (SPR) optical biosensing with advanced optics. Integrin moieties of $\alpha_{v} \beta_{3}$ were cross-linked to the flexible dextran matrix of the ProteOn sensor chip using the EDC/NHS coupling method by injecting the following reagents at a flow rate of $5 \mu \mathrm{L} / \mathrm{min}$ : $0.05 \mathrm{M}$ NHS-0.2 M EDC mixture, $\alpha_{\mathrm{v}} \beta_{3}(15 \mu \mathrm{g} / \mathrm{mL}$ in $10 \mathrm{mM} \mathrm{NaAc}, \mathrm{pH} 5)$, and $1 \mathrm{M}$ ethanolamine- $\mathrm{HCl}(\mathrm{pH} 8.5){ }^{21}$ Non-cross-linked ligands were removed by washing with buffer. Experiments were carried out at room temperature using three different NP samples: GE, GEH, and GEH-RGD. A solution of NPs at a concentration of $10 \mu \mathrm{g} / \mathrm{mL}$ was flown over the $\alpha_{v} \beta_{3}$ surfaces (as well as a control surface with no immobilized ligand) at $10 \mu \mathrm{L} / \mathrm{min}$ for 10 minutes, and the surfaces were then washed with buffer between injections to bring the resonance units (RU) values to baseline.

\section{In vitro evaluation}

\section{HUVEC culture and cytotoxicity evaluation of NPs}

HUVECs were cultured in M199 medium with 10\% FBS/ penicillin-streptomycin-neomycin addition, supplemented with ECGS $(30 \mu \mathrm{g} / \mathrm{mL})$, and heparin $(25 \mathrm{U} / \mathrm{mL})$. Cells were subcultured at a ratio of 1:3 seeding on a gelatin (type A, B300, 1\%) precoated dish, as recommended by the Bioresource Collection and Research Center. To evaluate the possible cytotoxic concentration, EGCG solution and various NP formulations (GE, GEH, and GEH-RGD) were added into the culture medium at an EGCG concentration ranging from 0.02 to $500 \mu \mathrm{g} / \mathrm{mL}$. Cell viability was examined by using the CCK-8 kit with WST-8 (2-[2-methoxy-4-nitrophenyl]-3[4-nitrophenyl]-5-[2,4-disulfophenyl]-2H-tetrazolium) 
reduction assay. A total of $5 \times 10^{3}$ cells in $100 \mu \mathrm{L}$ medium was seeded in 96-well plates and cultured overnight. Cells were rinsed twice with PBS, and $100 \mu \mathrm{L}$ of culture medium was added. NP suspensions $(100 \mu \mathrm{L})$ at different concentrations (diluted in culture medium) were applied to the cells and incubated for 1 and 3 days at $37^{\circ} \mathrm{C}$. Cell viability was determined by addition of WST- 8 reagent as indicated by the manufacturer. Cells cultured with culture medium only were used as controls. After 4 hours of incubation, the color of a small aliquot $(100 \mu \mathrm{L})$ of the solution was quantitatively assessed by using a microplate reader at $450 \mathrm{~nm}$ (Multiskan GO microplate spectrophotometer; Thermo Fisher Scientific). The percentage of viable cells was calculated by comparison to control cells, cultured with medium only. Cells were stained with a live/dead stain kit to observe cell viability. Images were acquired using an inverted fluorescence microscope (Olympus, IX81, Tokyo, Japan).

\section{Cellular uptake of variant form of GE based NPs}

For the uptake test, HUVECs were seeded in a 96-well plate overnight and then treated with GE, GEH, or GEH-RGD NPs at an EGCG concentration of $100 \mu \mathrm{g} / \mathrm{mL}$ for 2 hours. These NPs were loaded with TAMRA dye $(0.5 \mu \mathrm{g} / \mathrm{mL})$ for observation. The same concentration of TAMRA-dye solution was used to allow comparison. After incubation with NPs, cells were washed twice with PBS and fixed by $10 \%$ formaldehyde solution. Afterward, $0.1 \%$ Triton X-100 was added for 5 minutes, then washed by $2 \%$ FBS twice. The nucleus was stained with 4',6-diamidino-2-phenylindole (300 nM), followed by several washes with PBS. Cell samples were examined by an ImageXpress Micro XL wide-field high-content screen system (Molecular Devices, Sunnyvale, CA, USA) and analyzed using the MetaXpress 5 software. Within these images, NPs were defined by the minimum $(0.3 \mu \mathrm{m})$ and maximum $(3 \mu \mathrm{m})$ width. Nuclei were also defined by the minimum $(3 \mu \mathrm{m})$ and maximum $(15 \mu \mathrm{m})$ width. The number of particles/cell was counted as total number of particles/nucleus.

\section{HUVEC-migration assay}

Vascular endothelial cells must migrate to form new vessels, therefore the migration capacity of HUVEC after treated by chemicals was examined. Briefly, HUVECs $\left(2 \times 10^{5}\right.$ cells/well $)$ were seeded into a 24 -well plate with $0.1 \%$ gelatin pre-coating and incubated with complete medium at $37^{\circ} \mathrm{C}$ and $5 \% \mathrm{CO}_{2}$ overnight. A line of the cell layer was scrapped by using a $200 \mu \mathrm{L}$ tip, followed by three washes with PBS. Fresh medium containing different EGCG formulations, EGCG solution, GE, GEH, and GEH-RGD with the same EGCG concentration $(20 \mu \mathrm{g} / \mathrm{mL})$ was added to the cells. Three selected views along the scraped line in each well were photographed using an inverted microscope (BM-1A; Sage Vision, Taipei, Taiwan). Cells incubated with fresh medium were used as control. After 3, 6, and 24 hours of incubation, images were captured at $40 \times$ magnification. The average scraped area in each well was measured, and the change in area for each experimental condition was compared with that of the control. Migration rate was normalized by comparison to the initial gap distance in each group.

\section{Therapeutic evaluation in a corneal NV mouse model}

C57BL/6J black mice aged 8-14 weeks were used in this study. The experimental procedure was approved by the Institutional Animal Care and Use Committee of Taipei Medical University (approval LAC-101-0289). Sixty mice were used in this study for two repeat animal tests, and mice numbers in each group (normal, PBS, EGCG, GEH, and GEH-RGD) were six. Briefly, the mice were anesthetized to immobilize them before examination. Next, topical administration of $0.5 \%$ Alcaine for local anesthesia was performed, followed by pressing the tip of an applicator containing silver nitrate/potassium (Grafco) to the center of the cornea steadily for 8 seconds. ${ }^{22}$ The excess of nitrate was eliminated by washing with $5 \mathrm{~mL}$ of saline solution. A burned cornea causing opacity on the eye was observed. The saline was carefully wiped dry. Each mouse only suffered one burnt-eye treatment. The EGCG, GEH, or GEH-RGD NP solution diluted in PBS at a final EGCG concentration of 30 $\mu \mathrm{g} / \mathrm{mL}$ was applied on the mouse ocular surface as eyedrops twice daily (11:00 am and 4:30 pm) for 7 days. The burnstimulus response and severity of $\mathrm{NV}$ were then assessed in anesthetized mice by observation under a handheld portable slit lamp (SL-17; Kowa Co Ltd, Nagoya, Japan).

\section{Statistical analysis}

All data are expressed as mean \pm standard deviation from two to three independent experiments. Statistical differences between groups were tested by Student's $t$-test or one-way analysis of variance using SPSS 17.0 (SPSS Inc, Chicago, IL, USA). $P$-values of 0.05 were considered statistically significant.

\section{Results Characterization of RGD peptide-HA conjugate}

As shown in Figure 1A, the GRGDSPK peptide was conjugated with HA by the coupling reaction between the carboxyl groups of HA and amine groups of the RGD peptide using EDC/NHS. HA-RGD conjugation was used to modify the NP surface (Figure 1B) to form targetable carriers recognizing 
vascular endothelial cells by binding with integrin $\alpha_{\mathrm{v}} \beta_{3}$ expressed on their surface. The FT-IR spectra of HA, RGD peptide, HA/RGD mixture, and conjugated form (HA-RGD) are shown in Figure 2A. The HA/RGD mixture presented an additional FT-IR pattern compared to its individual pattern.
However, the HA-RGD conjugate presented more changes in the carbonyl region, affecting the relative ratio between amides and carboxylates when the RGD peptide was grafted to HA. The relative decrease of the carboxylate-associated peaks (protonated carboxylic acids at $1,720 \mathrm{~cm}^{-1}$, asymmetric
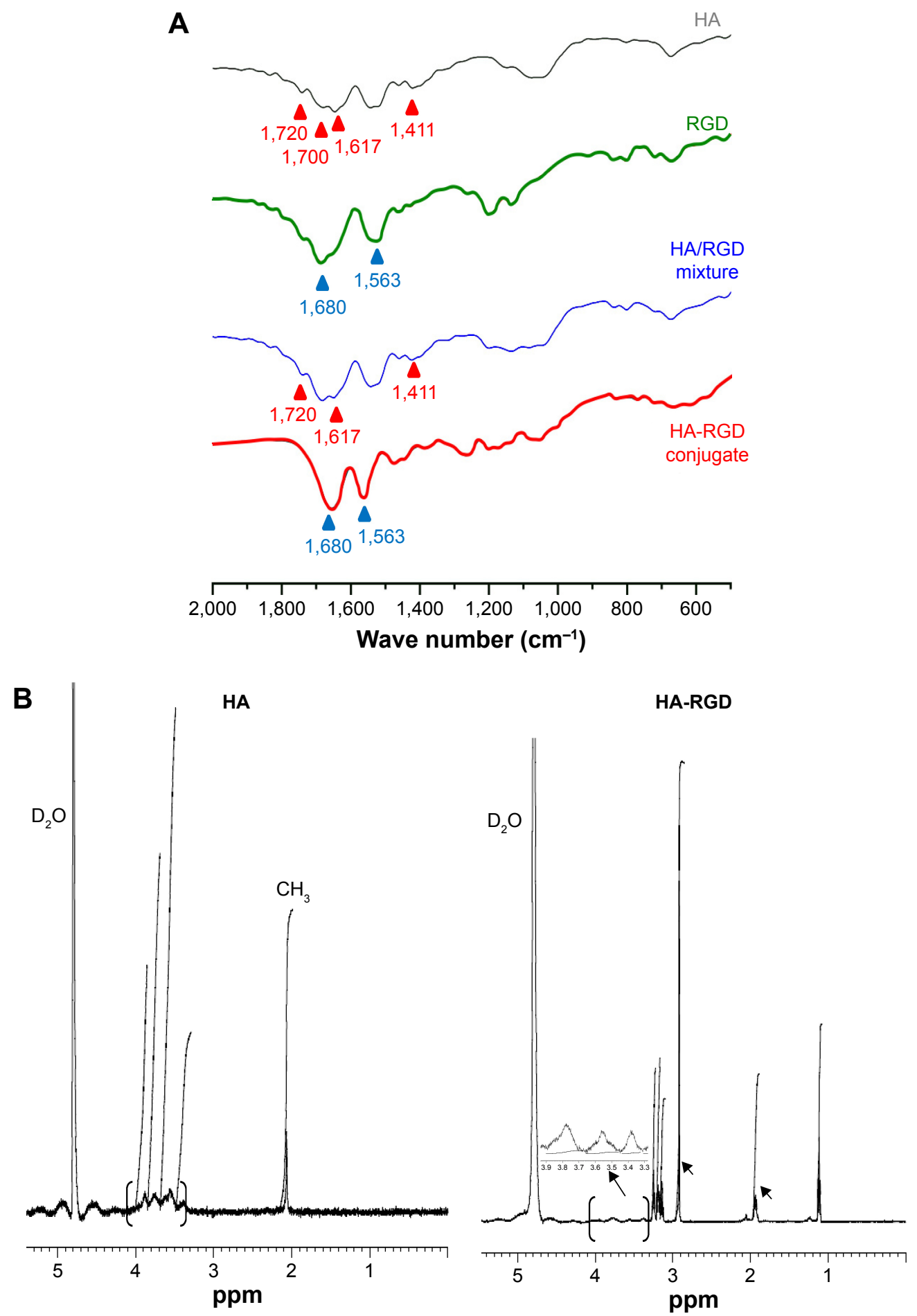

Figure 2 (A) FT-IR patterns of HA, RGD peptide, their mixture, and the conjugated product (HA-RGD); (B) 'H-NMR spectra of HA and HA-RGD conjugates. Note: The arrows indicate the acetamido moiety of the $\mathrm{N}$-acetyl-D-glucosamine residue of HA and proline in GRGDSPK.

Abbreviations: FT-IR, Fourier-transform infrared; HA, hyaluronic acid; RGD, arginine-glycine-aspartic acid; NMR, nuclear magnetic resonance; GRGDSPK, H-Gly-ArgAsp-Ser-Pro-Lys-OH. 
stretching band at $1,617 \mathrm{~cm}^{-1}$, and symmetric stretching band at $1,411 \mathrm{~cm}^{-1}$ ) and the relative increase of the amide ones (eg, amide I at 1,680 $\mathrm{cm}^{-1}$ ) were recorded in the HA-RGD conjugate (Figure 2A). The ${ }^{1} \mathrm{H}-\mathrm{NMR}$ spectrum of HA-RGD in $\mathrm{D}_{2} \mathrm{O}$ is shown in Figure $2 \mathrm{~B}$. The acetamido moiety of the $N$-acetyl-D-glucosamine residue of HA (Figure 2B) was located at $\delta=1.9 \mathrm{ppm}$, as previously described. ${ }^{18,23}$ Fingerprints of HA skeletal signals at $\delta=3.4-3.9$ ppm were observed, and $2.075 \mathrm{ppm}$ for $\mathrm{CH}_{3}$ and anomeric resonance at 4.4-4.6 $\mathrm{ppm}^{24}$ were also detected. The magnification of the bracket in Figure 2B represents the skeletal signal of HA in the HA-RGD pattern, which can also be traced. In particular, the peaks at $\delta=1.99,3.41$, and 4.12 ppm corresponded to the ring structure of proline, ${ }^{25}$ confirming the conjugation of RGD with HA (Figure 2B).

\section{Characterization of HA-RGD-modified NPs with EGCG encapsulation}

Figure 1B shows a schematic for the preparation of GE NPs as the raw NPs. Their surfaces were then decorated with HA or HA-RGD, shown as GEH and GEH-RGD, respectively. The particle sizes of GE, GEH, and GEH-RGD were $118.77 \pm 21.06$, $303.73 \pm 50.38$, and $168.87 \pm 22.5 \mathrm{~nm}$, respectively (Table 1). The GE presented a positive surface, with a $\zeta$-potential value at $23.7 \pm 2.1 \mathrm{mV}$. The $\zeta$-potential of GE with additional HA became more negative. In this study, $0.25 \%$ (wt/v) HA was used for GEH preparation. The average $\zeta$-potentials of GEH and GEH-RGD were opposite. The average $\zeta$-potential of GEH was $-11.3 \pm 0.4 \mathrm{mV}$ and that of GEH-RGD was $19.7 \pm 2 \mathrm{mV}$. All NPs with low polydispersity-index value (Table 1) presented as monodispersed colloidal systems with narrow size distribution (Figure 3A). The EGCG-encapsulation rates of these three nanoformulations were all higher than 95\% using a free radical reduction method (ABTS, Table 1). GEH-RGD presented as round particles with a spherical structure, as assessed by TEM examination (Figure 3B), and its size was around $200 \mathrm{~nm}$, which was comparable to the DLS result. The TEM images of GE and GEH showed that they presented similar structures (data not shown).

Table I Characterization of nanoparticle variants

\begin{tabular}{lllll}
\hline & $\begin{array}{l}\text { Particle } \\
\text { size }(\mathbf{n m})\end{array}$ & $\begin{array}{l}\text { ל-potential } \\
(\mathbf{m V})\end{array}$ & $\begin{array}{l}\text { EGCG } \\
\text { ER (\%) }\end{array}$ & PDI \\
\hline GE & $118.77 \pm 21.06$ & $23.7 \pm 2.1$ & $98.03 \pm 0.47$ & $0.15 \pm 0.02$ \\
GEH & $303.73 \pm 50.38$ & $-11.3 \pm 0.4$ & $97.46 \pm 0.28$ & $0.18 \pm 0.02$ \\
GEH-RGD & $168.87 \pm 22.50$ & $19.7 \pm 2.0$ & $97.13 \pm 0.55$ & $0.25 \pm 0.03$ \\
\hline
\end{tabular}

Note: Values represent mean \pm standard deviation $(n=6)$.

Abbreviations: EGCG, epigallocatechin-3-gallate; ER, encapsulation rate; PDI, polydispersity index; GE, gelatin-EGCG; GEH, GE-hyaluronic acid; RGD, arginineglycine-aspartic acid.
For the drug-release assay, a red fluorescent dye (TAMRA) was used and the fluorescence intensity detected. PBS with an adjusted $\mathrm{pH}$ value of 4 was chosen to mimic the acidic environment in lysosomes. The amount of dye release from the TAMRA solution (free dye) indicated a quick release up to $86 \% \pm 2.14 \%$ from the beginning to 5 hours later (Figure 3C). NP groups (GE, GEH, and GEH-RGD) exhibited very slow release of TAMRA dye after even 5 hours. Only about $6.18 \% \pm 2.43 \%$ cumulated release was recorded in the GEH-RGD group, and the release was sustained thereafter, lasting up to 30 hours and accumulating to $29.14 \% \pm 3 \%$ (Figure 3C).

\section{GEH-RGD recognizes $\alpha_{v} \beta_{3}$ integrin via the RGD conjugate}

Integrin recognition of the NPs was examined to determine the binding ability of the RGD peptide to the $\alpha_{\mathrm{v}} \beta_{3}$-grafted sensor chip. Results from the SPR are shown in Figure 4. In each case, the amount of protein bound is represented as the difference in signal between the initial baseline signal (buffer flow) and the final signal when the buffer was reintroduced. As shown in Figure 4A, GEH-RGD bound to $\alpha_{\mathrm{v}} \beta_{3}$ on the chip quickly, and the signal was stronger than that of GE. It appeared that a higher amount of GEH-RGD was trapped on the $\alpha_{v} \beta_{3}$-grafted sensor chip. Figure 4B shows that GEH-RGD also presented a higher SPR signal than GEH. Although GE or GEH NPs had no RGD peptide on their surface, the change in SPR signal may have resulted from the adsorption of NPs on the chip surface. Positive particles (GE) showed stronger attraction to integrin than negative particles (GEH). Overall, GEH-RGD presented the strongest RU value recorded from the $\alpha_{\mathrm{v}} \beta_{3}$-grafted sensor chip.

\section{HUVECs respond to GEH-RGD NPs in vitro} HUVEC viability significantly inhibited by GEH-RGD The cell viability of HUVECs was tested by incubation with various NP formulations at different EGCG concentrations, including medium only as the control group. When cells were cultured at high EGCG concentrations $(200 \mu \mathrm{g} / \mathrm{mL})$, cell viability was significantly decreased in all groups at days 1 and $3(<10 \%$, Figure 5A). After 1 day's treatment, the GEH-RGD group showed the highest reduction in cell viability $-82.17 \% \pm 7.82 \%$ at an EGCG concentration of $20 \mu \mathrm{g} / \mathrm{mL}$ - lasting until day 3 , with a decrease in cell viability to $64.22 \% \pm 6.2 \%$. A similar tendency was also observed with a lower EGCG concentration $(2 \mu \mathrm{g} / \mathrm{mL})$. Compared to other groups (EGCG solution, GE, and 

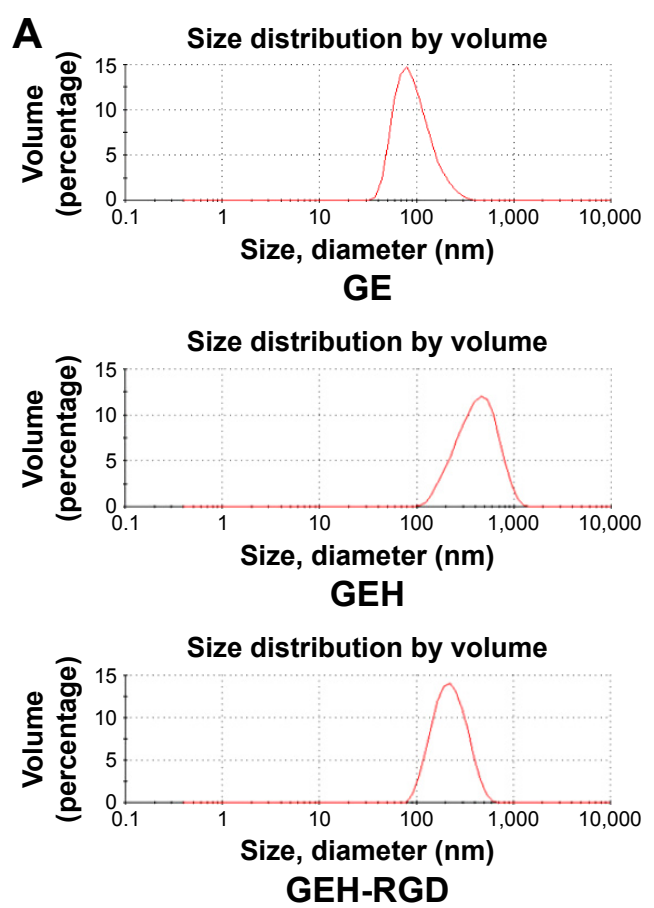

B

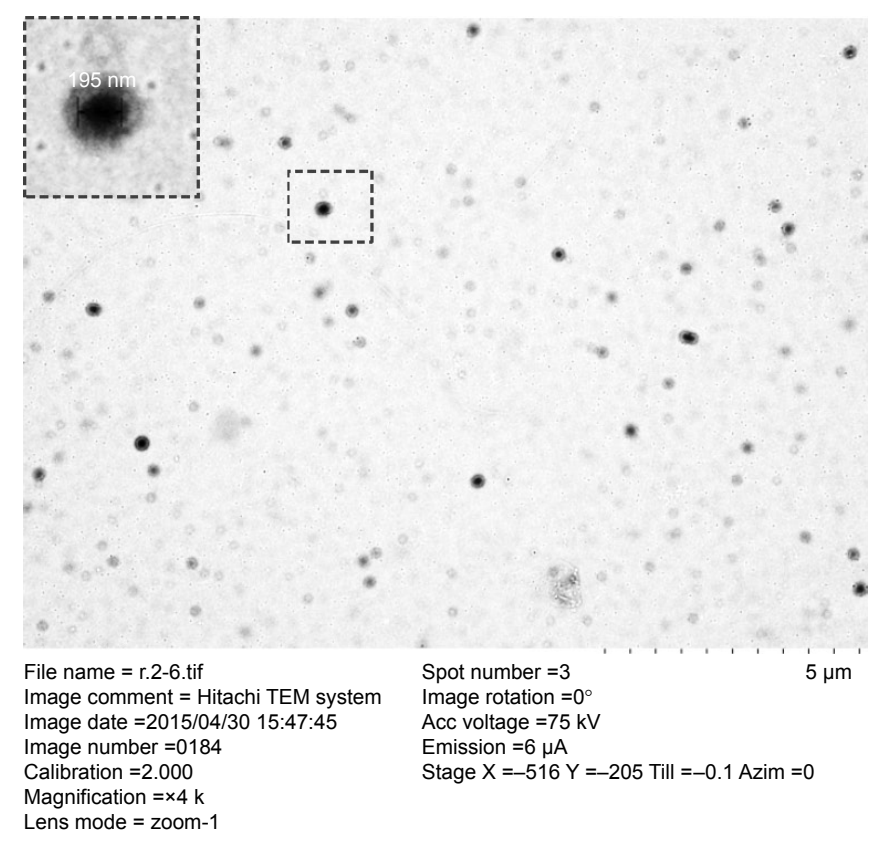

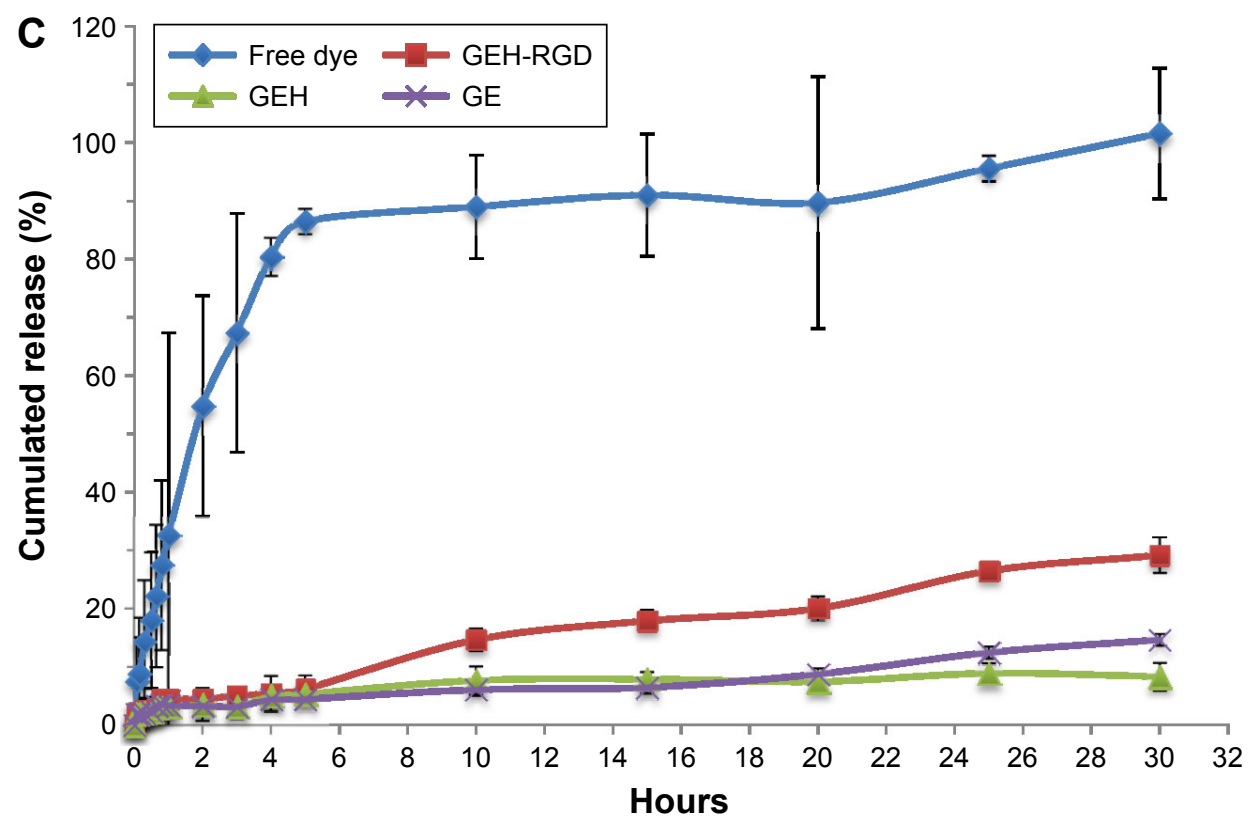

Figure 3 (A) DLS size distribution of NPs; (B) TEM of GEH-RGD; (C) release pattern of variant NPs in PBS (pH 4) at $37^{\circ} \mathrm{C} \pm 0.5^{\circ} \mathrm{C}$.

Abbreviations: DLS, dynamic light scattering; NPs, nanoparticles; TEM, transmission electron microscopy; GEH, gelatin-epigallocatechin-3-gallate-hyaluronic acid; RGD, arginine-glycine-aspartic acid; PBS, phosphate-buffered saline.

GEH), GEH-RGD effectively reduced cell viability at a lower EGCG concentration at days 1 and 3. The images of HUVECs labeled using the live/dead stain are shown in Figure 5B. The live cells emitted green fluorescence and the dead cells red fluorescence. A large percentage of live cells presented with green spots in the control group at days 1 and 3. All cells were damaged and died (many red spots, but no green stains) in cultures treated with a high EGCG concentration $(200 \mu \mathrm{g} / \mathrm{mL})$, regardless of whether the drug was free or conjugated to any of the three NPs, as shown in Figure 5B. At low EGCG concentration (20 $\mu \mathrm{g} / \mathrm{mL}$ ), the viability of cells treated with the EGCG solution, GE, and GEH was high, but that of cells treated with GEH-RGD was low, due to the efficacy of GEH-RGD in 

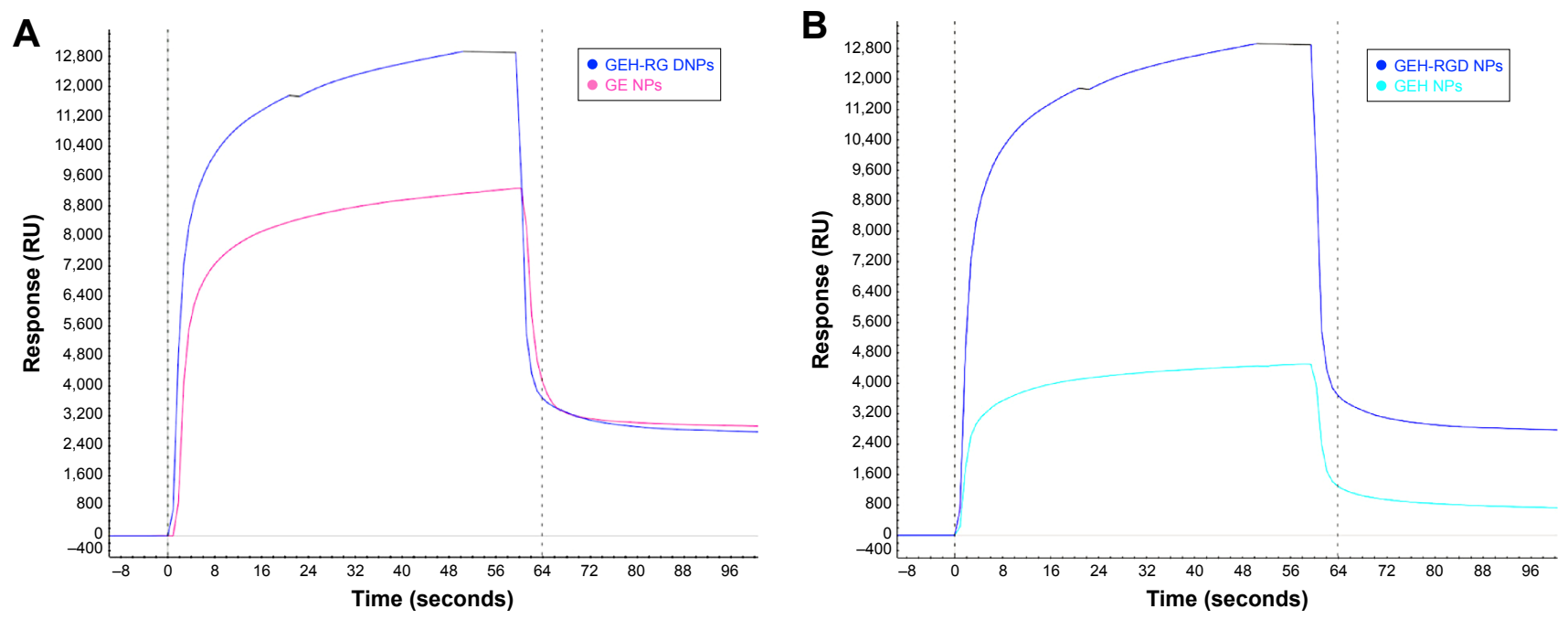

Figure 4 SPR analysis of the binding affinity of NPs with the integrin $\alpha_{\vee} \beta_{3}$, grafted on a chip.

Notes: (A) GEH-RGD presented a stronger signal than GE; (B) GEH-RGD signal was also stronger than that of GEH.

Abbreviations: SPR, surface plasmon resonance; NPs, nanoparticles; GEH, gelatin-epigallocatechin-3-gallate-hyaluronic acid; RGD, arginine-glycine-aspartic acid; GE, gelatin-EGCG; EGCG, epigallocatechin-3-gallate.

targeting these cells (Figure 5B). These results indicate that compared with other formulations, GEH-RGD was more toxic to HUVEC cells, causing a reduction in cell viability even when using the same EGCG concentration $(20 \mu \mathrm{g} / \mathrm{mL})$. No significant difference was observed between the GE and GEH groups in terms of cell viability. Therefore, only GEH and GEH-RGD, which present a similar chemical composition on their surface, were tested in experiments thereafter.

\section{GEH-RGD NPs observed in HUVECs}

The distribution of NPs with fluorescence (TAMRA) labeling was examined via the ImageXpress imaging system after 2 hours of incubation with HUVECs. As shown in Figure 6A, almost no red spots were observed in cells in the TAMRA group (dye solution). Cells treated with GEH-RGD NPs displayed more red spots in the cytoplasm and membrane, indicating that the enhanced uptake of targeted NPs (GEHRGD) by HUVECs was mediated by a specific RGD $-\alpha_{v} \beta_{3}$ interplay. From the image-quantification results, in the free dye (TAMRA) solution ( $2 \pm 5$ particles/ 100 cells), a very low fluorescence signal was detected as the control group was tested (Figure 6B). In the GEH group, $22 \pm 5$ particles/ 100 cells were counted (Figure $6 \mathrm{~B}$ ), while $51 \pm 9$ particles $/ 100$ cells were counted in the GEH-RGD group. The GEH-RGD-treated cells presented about twice the number of NPs than cells from the GEH group after 2 hours of culture. This finding is consistent with the SPR assay, indicating that GEH-RGD with the GRGDSPK peptide modified on its surface can target $\alpha_{v} \beta_{3}$ on vascular endothelial cells.

\section{GEH-RGD NPs effectively inhibited HUVEC migration}

To determine whether EGCG in different formulations was capable of influencing the migration of HUVECs, cells were treated with different formulations of EGCG $(20 \mu \mathrm{g} / \mathrm{mL})$ in a 2-D migration assay. Gaps of about $500 \mu \mathrm{m}$ were created on the HUVEC layer in all groups (Figure 7A). HUVECs obviously migrated in the control group after 6 hours, the gap between the two edges was closed, and the edge line was no longer detectable after 24 hours, as shown in Figure 7A. The migration rate was not significantly different between the different EGCG groups after 6 hours of treatment, but was significantly lower than the control group. After 24 hours of coculture with NPs, differences in the gap closure were observed between groups. The GEH-RGD-treated cells showed the widest length $(208.6 \pm 18.4 \mu \mathrm{m})$, with very low cell migration compared with control, EGCG, and GEH NPs (Figure 7A). The migration rate was calculated by comparing with the initial gap distance, and its shown as percentage in Figure 7B. The migration rate in the GEH-RGD-treated cells was $58.6 \% \pm 7.92 \%$, while the migration rates in the control, EGCG, and GEH groups were $88 \% \pm 4.27 \%, 72.8 \% \pm 2.8 \%$, and $82.4 \% \pm 2.15 \%$, respectively. GEH-RGD NPs strongly inhibited HUVEC migration for up to 24 hours.

\section{Antiangiogenic effect of GEH-RGD NPs used as eyedrops in a corneal NV mouse model}

The visual grading on the last day of treatment allowed us to observe the appearance and severity of the corneal $\mathrm{NV}$ in mice. When new vessels grow, they can reach the 


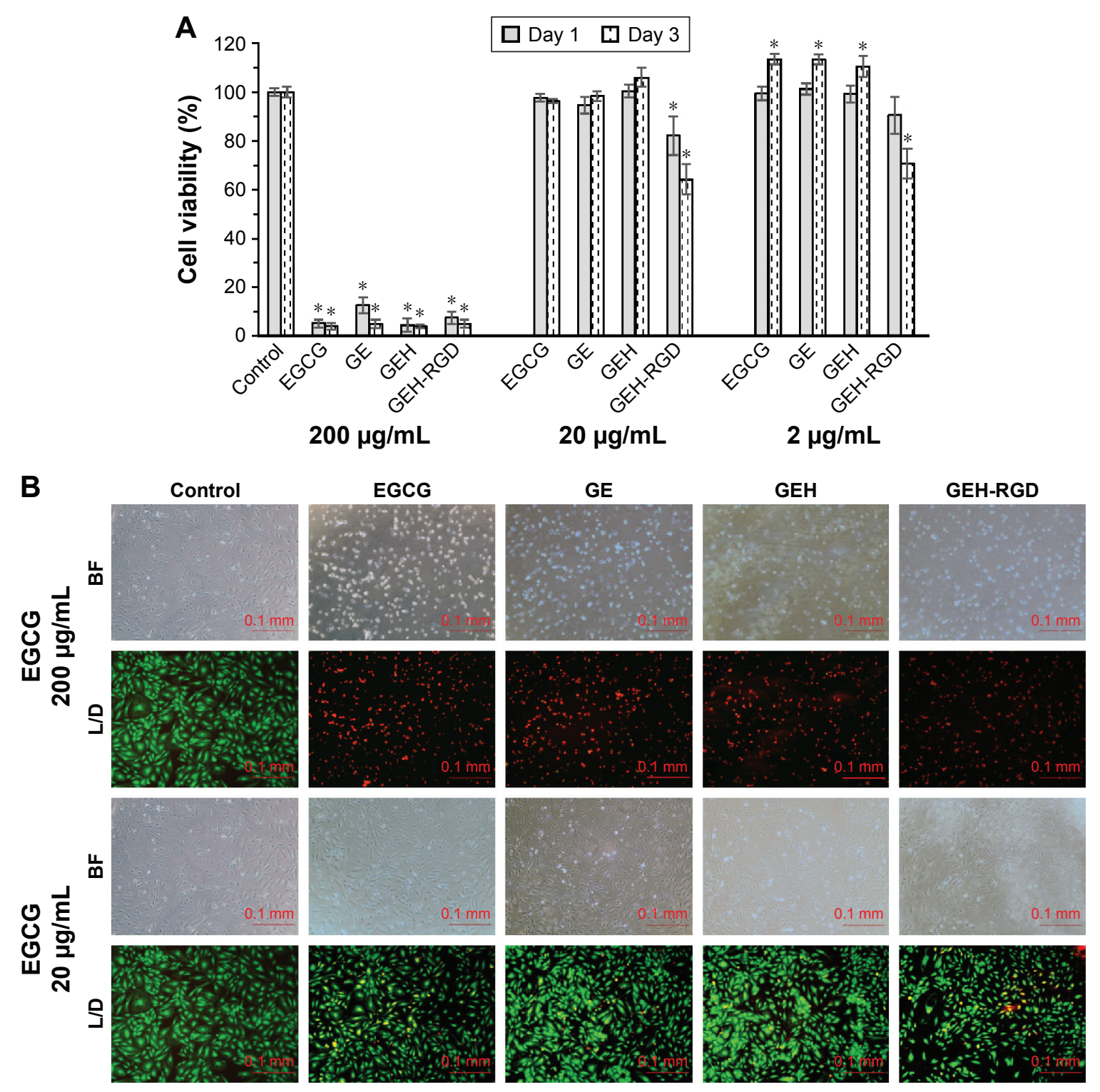

Figure 5 Results of cell viability and live/dead stain assays.

Notes: (A) Cell viability of HUVECs treated with various NP formulations at different EGCG concentrations; (B) live/dead cells identified by fluorescence (scale bars $100 \mu \mathrm{m}$ ) of HUVECs cultured in medium (control), EGCG, GE, GEH, and GEH-RGD NPs at an EGCG concentration of $200 \mu \mathrm{g} / \mathrm{mL}$ or $20 \mu \mathrm{g} / \mathrm{mL}$ at day I. Results expressed as mean \pm standard deviation $(\mathrm{n}=6) ; * \mathrm{P}<0.05$.

Abbreviations: HUVECs, human umbilical vein endothelial cells; NP, nanoparticle; EGCG, epigallocatechin-3-gallate; GE, gelatin-EGCG; GEH, GE-hyaluronic acid; RGD, arginine-glycine-aspartic acid; BF, bright field; L/D, live/dead.

burn scar, appearing as a white patch. PBS-treated animals were used as negative controls. For the in vivo study, the EGCG concentration was $30 \mu \mathrm{g} / \mathrm{mL}$ to increase the drug bioavailability on the ocular surface, because the drug was delivered as eyedrops. A prevention effect was observed by regression of pathological NV on the damaged cornea on the seventh day. High-density vessels surrounding the entire eyeball were observed in the PBS and EGCG groups (Figure 8). In contrast, lower vessel density and thinner newly grown vessels were observed in the GEH and GEH-RGD groups. A clearer cornea and even a cornea with no vessel were detected in mice treated with GEH-RGD. This tendency showed that the targetable NPs (GEH-RGD) were more effective in preventing and inhibiting the development of the pathological vessels in the cornea (Figure 8).

\section{Discussion}

NV is a complex process that includes the activation, proliferation, and migration of endothelial cells, the disruption of the vascular basal membrane, the formation of vascular tubes and networks, and the formation of connections. ${ }^{26}$ Cornea or conjunctiva injection of anti-VEGF antibody therapy (eg, bevacizumab) is the main approach to treat 
A

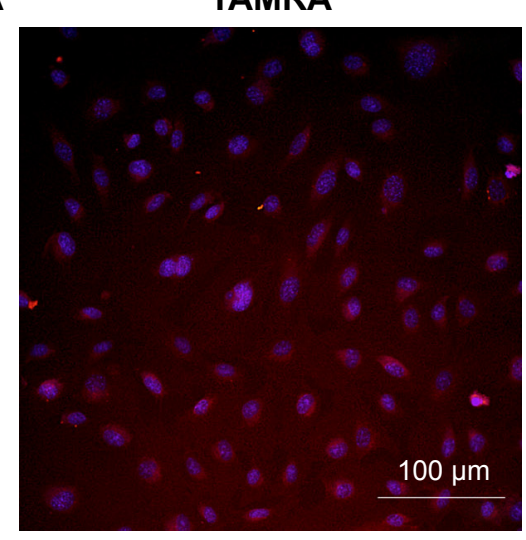

GEH

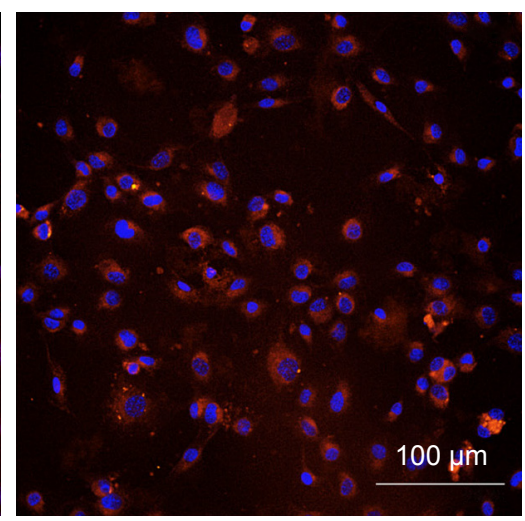

GEH-RGD

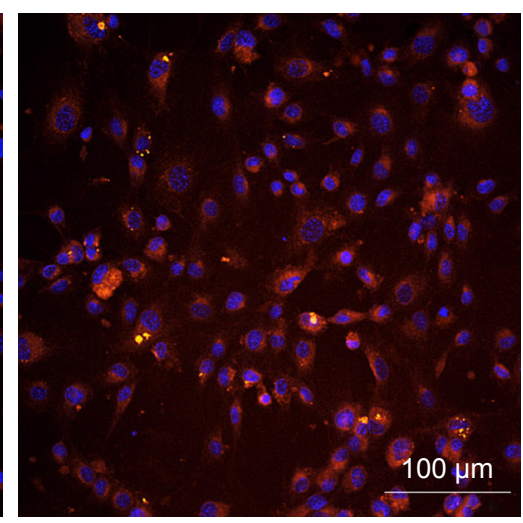

B

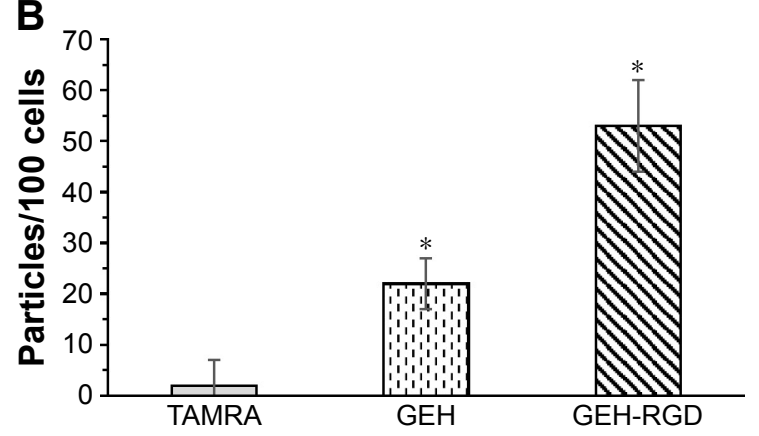

Figure 6 (A) TAMRA, GEH, and GEH-RGD taken up by HUVECs after 2 hours of coculture; (B) quantification of NPs in cells from A.

Notes: Vertical bars represent standard error of mean $(n=3) ; * P<0.05$.

Abbreviations: TAMRA, carboxytetramethylrhodamine; GEH, gelatin-epigallocatechin-3-gallate-hyaluronic acid; RGD, arginine-glycine-aspartic acid; HUVECs, human umbilical vein endothelial cells; NPs, nanoparticles.

corneal NV. It is an invasive and painful treatment for patients. Besides, studies indicate that angiogenesis is redundantly regulated and carried out with/without the direct involvement of the VEGF pathway. ${ }^{27,28}$ Corneal $\mathrm{NV}$ can result from infection, inflammation, and trauma. Anti-VEGF antibody therapy works only on the developed vascular system. It has no beneficial effect on inflammation or other factors causing corneal angiogenesis. Therefore, a drug with antiangiogenic and anti-inflammatory effects is needed to treat corneal NV. As such, chemicals with a broad pattern for angiogenesis inhibition should be considered. The antiangiogenic and anti-inflammatory activities of EGCG have been widely demonstrated in vitro and in vivo. ${ }^{12,15,29,30}$ Therefore, EGCG is a good candidate for topical treatment to limit inflammation and vessel growth in corneal NV.

Eyedrops present an advantageous route for delivery of medications to the ocular surface, because they are noninvasive and produce minimal adverse effects compared to systemic administration. ${ }^{8}, 10$ However, the topical application of EGCG may present some limitations, because the corneal epithelium forms a barrier to drug penetration. Therefore, a high concentration of EGCG is required to increase the bioavailability of the drug on the eyes. High concentrations of EGCG could cause erythema of the ocular surface, due to its acidic nature (about $\mathrm{pH} 4$ ) and the associated production of $\mathrm{H}_{2} \mathrm{O}_{2}$, which injures corneal cells. ${ }^{28}$ These limitations can be easily solved by encapsulation of EGCG in a drug carrier. Encapsulation in a nanocarrier could also protect EGCG from oxidation during transportation. Li and Gu showed that EGCG-ovalbumindextran conjugate NPs significantly enhanced the permeability of EGCG on Caco2 cell monolayers, colon epithelium with tight junction similar to the corneal epithelium, compared with EGCG solution, ${ }^{31}$ suggesting that these NPs improved the absorption of EGCG in cells.

Many ocular diseases are treated with topical application of eyedrops. The major disadvantages of this dosage include tear screening, nasolacrimal duct drainage, and cornea barriers, reducing the drug bioavailability in the eyes. Different studies have shown the potential of NPs for either gene or drug delivery for ophthalmic application. ${ }^{10,32-35}$ Application of NPs for corneal NV is becoming more popular. ${ }^{36,37}$ Curcumin, the yellow extract from Curcuma longa, presents anti-inflammatory and antiangiogenic activities. It has been loaded in methoxypolyethylene glycol-poly$\varepsilon$-caprolactone NPs delivered to corneal NV rats as eyedrops, 


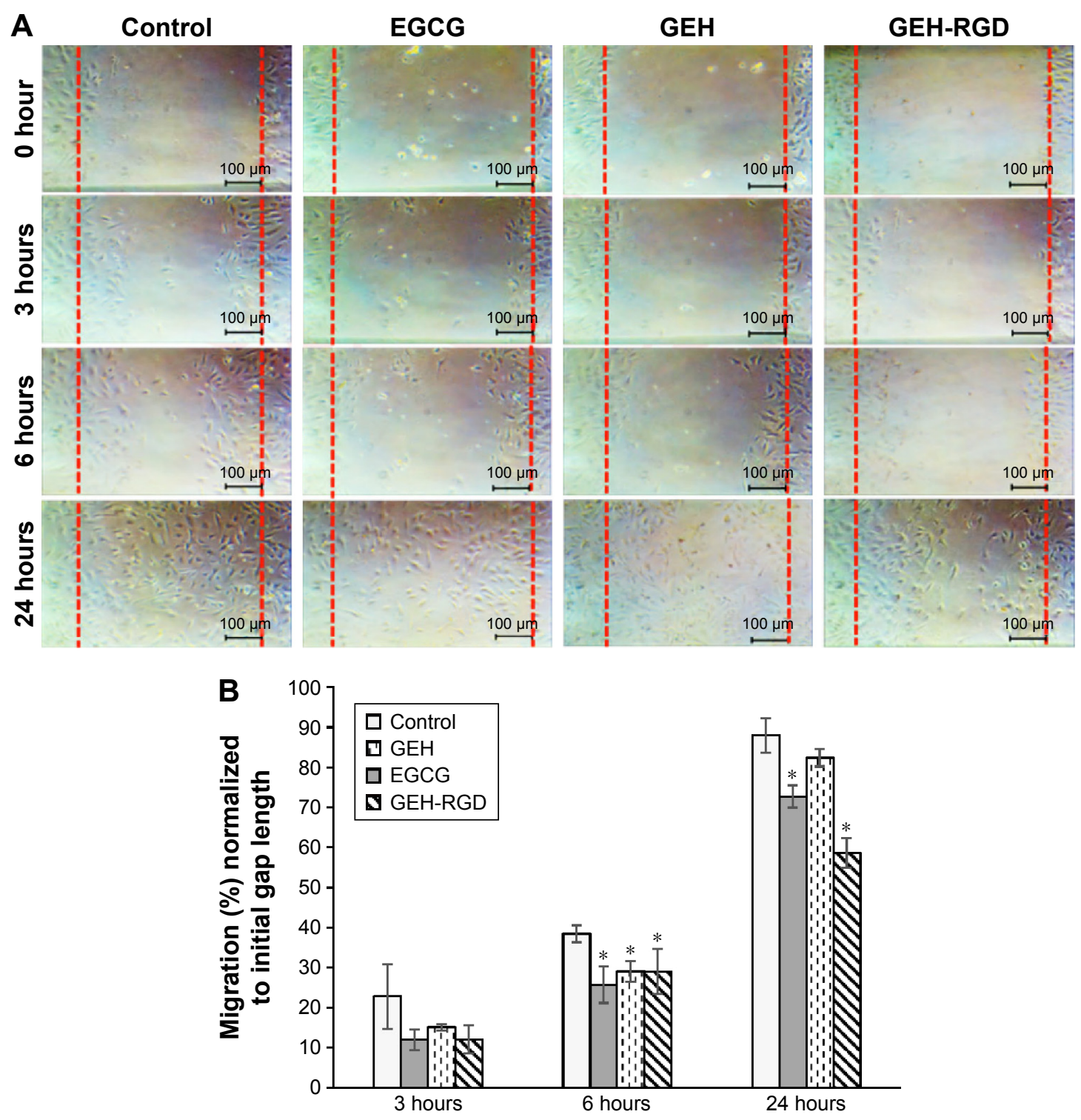

Figure 7 (A) Migration assay: photomicrographs of the wound closure. (B) Migration rate of HUVECs treated with EGCG, GEH, and GEH-RGD Notes: All groups were treated with the same EGCG concentration $(20 \mu \mathrm{g} / \mathrm{mL}) ;{ }^{*} \mathrm{P}<0.05$.

Abbreviations: HUVECs, human umbilical vein endothelial cells; EGCG, epigallocatechin-3-gallate; GEH, gelatin-EGCG-hyaluronic acid; RGD, arginine-glycine-aspartic acid.

showing enhanced retention of curcumin in the cornea and significant improvement in prevention of corneal NV over free curcumin. ${ }^{36}$ Our previous study showed that cationic gelatin NPs (GNPs) can be attracted to rabbit cornea and retained in the cornea for a longer time. ${ }^{38}$ Therefore, GNPs with positive charge are promising as vehicles for ocular drug delivery.

In this study, RGD peptides with GRGDSPK sequence were conjugated to HA to recognize the $\alpha_{\mathrm{v}} \beta_{3}$ integrin on HUVECs. Because HA presents many carboxyl groups on the side chain, it is easy to conjugate $\mathrm{NH}_{2}$ - $\mathrm{RGD}$ onto HA by EDC chemistry (Figure 1A). GE was synthesized according to a self-assembling method (Figure 1B). The HA-RGD ${ }^{1} \mathrm{H}-\mathrm{NMR}$ pattern was similar to that reported previously. ${ }^{18}$
NPs with surface decoration with targetable RGD ligand (GEH-RGD) were successfully prepared to increase the recognition of vascular endothelial cells.

To characterize these NPs, $\zeta$-potential and size of the HA- or HA-RGD-coated GE were measured to monitor the coating process. As shown in Table 1, $\zeta$-potential of the GE NPs presented a positive value at $23.7 \mathrm{mV}$, indicating that the particles were covered with an excess of positively charged gelatin molecules. The positive charges on GE NPs decreased with the addition of HA. When HA was added $(0.25 \% \mathrm{w} / \mathrm{v})$ to form $\mathrm{GEH}, \zeta$-potentials reached $-11.3 \mathrm{mV}$ (Table 1). This indicates that HA was deposited onto the GE NPs, leading to the formation of GEH ternary complexes. 
PBS

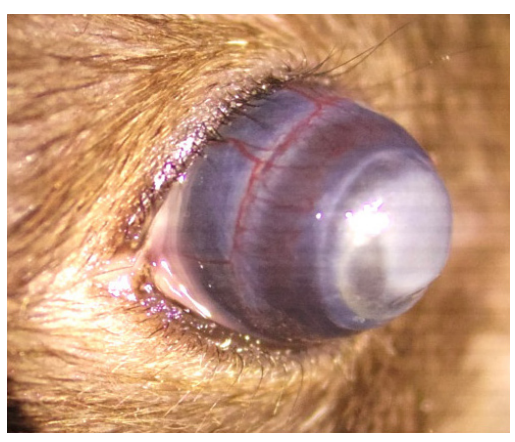

GEH

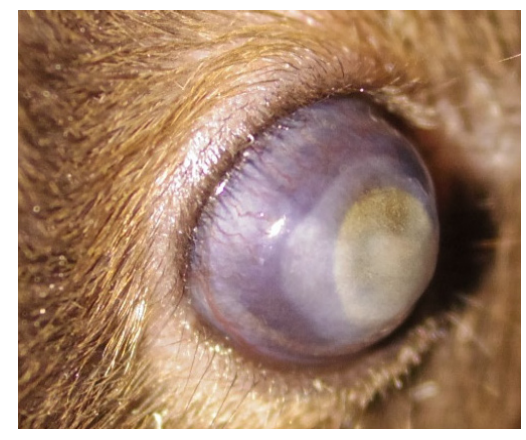

EGCG

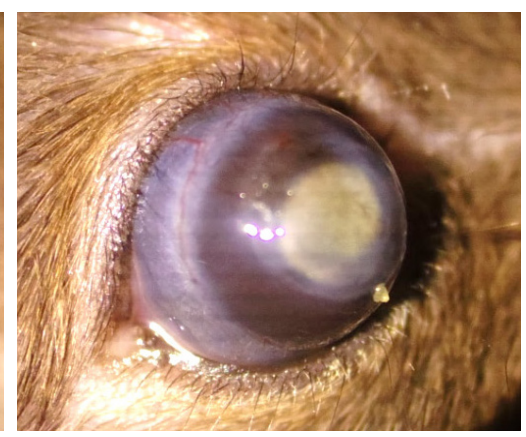

GEH-RGD

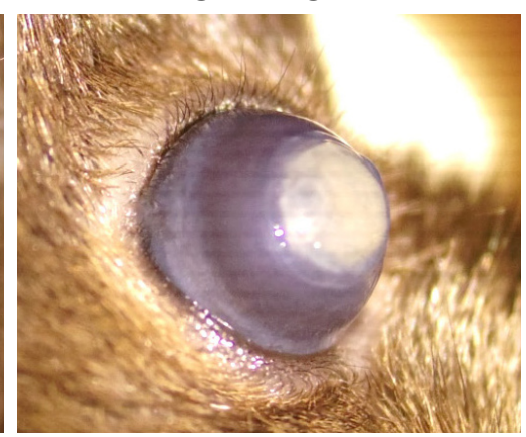

Figure 8 GEH-RGD NPs used as eyedrops prevent corneal NV formation.

Notes: The ocular images show angiogenesis in the PBS group. Vessel reduction was observed in corneas treated with free EGCG and EGCG NPs, especially when treated with GEH-RGD (EGCG $30 \mu \mathrm{g} / \mathrm{mL}$ twice daily).

Abbreviations: GEH, gelatin-epigallocatechin-3-gallate-hyaluronic acid; RGD, arginine-glycine-aspartic acid; NPs, nanoparticles; NV, neovascularization; PBS, phosphatebuffered saline; EGCG, epigallocatechin-3-gallate.

The HA addition resulted in a negatively charged surface, as previously shown. ${ }^{18}$ Size increased with the addition of $\mathrm{HA}$, because more and more HA molecules were coated on GE NPs (GE $118.77 \pm 21.06 \mathrm{~nm}$ vs GEH $303.73 \pm 50.38 \mathrm{~nm}$ ). However, the $\zeta$-potential of the GEH-RGD became positive $(19.7 \pm 2 \mathrm{mV})$ and its size smaller $(168.87 \pm 22.5 \mathrm{~nm})$. The gelatin concentration for prepared GE-based NPs was $0.44 \mathrm{w} / \mathrm{v} \%$. This is a low concentration, and all the prepared NPs were stored in water (not as dried powder). Besides, comparing the size acquired from TEM results (in a dry condition, its size is about $195 \mathrm{~nm}$ ) and DLS results (hydration condition, size $168.87 \pm 22.5 \mathrm{~nm}$ ), there was no obvious size difference between dry and water-content conditions, so we think there was no obvious swelling in GE-based NPs.

The side chain of GRGDSPK presents more amide groups. Therefore, $\mathrm{NH}_{3}{ }^{+}$resulted in the positive charge of HA-RGD. GEH-RGD particles presented a positive $\zeta$-potential. RGDSPK peptide interacts with HA, altering the spatial organization of the HA network, each HA chain is decorated by several peptides, turning it into a branched molecule, enabling complexation between the charged arginine or aspartic acid on RGD and the oppositely charged HA backbone or peptides in a neighboring molecule, eventually creating new entanglements between the domains. ${ }^{39}$ Therefore, the electrical attraction between HA and RGD resulted in a dense HA-RGD structure lining on the surface, presenting smaller particle size compared with a loose of HA molecules on its surface. Overall, GEH-RGD particles were successfully synthesized in round spheres with narrow size distribution (Figure 3A and B). Release of free dye (TAMRA) in solution was very fast (Figure 3C), which was otherwise slow from NPs (GE, GEH, and GEH-RGD), indicating a controllable system with constant release. ${ }^{31}$

The role of receptor-mediated endocytosis is to internalize ligands following proteolytic degradation in acidic $\mathrm{pH}$ of the endosomal/lysosomal compartments. After uptake, NPs can be shipped to primary endosomes and then transported to secondary endosomes, which then fuse with lysosomes. ${ }^{40}$ Lysosomes are a strong digestion system, and are the key clearance mechanism of NP elimination. The ability of NPs to escape endolysosomes depends on the surface charge of the NPs. ${ }^{41}$ For the release test in this study, fivefold-concentrated NPs (GE, GEH, and GEH-RGD) were used for getting highenough concentration after being released into PBS for quantification. These concentrated NPs were precipitated in PBS at $\mathrm{pH} 7$ (data not shown), and became a noncolloidal solution, 
and the release pattern at $\mathrm{pH} 7$ cannot reflect the real behavior of the colloidal solution. However, these NPs were still well suspended in PBS at pH 4. Therefore, we showed the release pattern of GE-based NPs tested in PBS at pH 4, which fits the colloidal condition and also mimics the acidic environment in lysosomes. A similar released pattern was revealed by EGCG-ovalbumin-dextran conjugate NPs treated in simulated gastric fluid at $\mathrm{pH} 4{ }^{42}$ The size and surface charge of protein-based NPs depend on $\mathrm{pH}$ conditions. Weakened repulsion among the NPs causes particle precipitation when the $\mathrm{pH}$ is around the isoelectric point of the selected proteins. ${ }^{43}$ Therefore, it is important to learn changes in particle size and $\zeta$-potential under different $\mathrm{pH}$ conditions. At $\mathrm{pH} 4$, about $6.18 \% \pm 2.43 \%$ of TAMRA from GEH-RGD diffused across the dialysis membrane after 5 hours, whereas about $30 \%$ of TAMRA released from precipitated GEH-RGD at $\mathrm{pH} 7$, which was faster than that at $\mathrm{pH} 4$ (data not shown). This result is consistent with a previous report on gelatindextran-tea polyphenol self-assembled NPs, a pH-dependent assembly of NPs, in which larger particles were formed at higher $\mathrm{pH}$, due to the weak interaction between gelatin and tea polyphenol. ${ }^{43}$ Upon internalization, NPs can either be delivered into the endo-/lysosome for release of bioactive compounds by degradation or escape the endo-/lysosome to reach the basolateral side by exocytosis. Therefore, a higher intracellular release rate of GE, GEH, or GEH-RGD can be predicted. The sustained release of TAMRA from GE, GEH, and GEH-RGD might be higher in the cytoplasm due to enzymatic degradation for future drug release.

During vascular remodeling and angiogenesis, several integrins are expressed on endothelial cells to potentiate cell invasion and proliferation. Integrin $\alpha_{\mathrm{v}} \beta_{3}$ is involved in ocular angiogenesis. ${ }^{16} \mathrm{VEGF}$, antibody blocking, and immunoconjugate drug therapy targeting integrin $\alpha_{\mathrm{v}} \beta_{3}$ inhibit $\mathrm{NV}$ in corneal/choroidal NV. ${ }^{16,44,45}$ The corneal epithelium and stroma express $\alpha_{2} \beta_{1}$ as well as $\alpha_{11} \beta_{1}$, while the normal epidermis and corneal epithelium lack $\alpha_{5} \beta_{1}$ and $\alpha_{\mathrm{v}} \beta_{3}{ }^{46,47}$ Therefore, integrin $\alpha_{\mathrm{v}} \beta_{3}$ heterodimers on vascular endothelial cells could be recognized by GEH-RGD from the interaction of RGD on the particles. The whole uptake process of NPs by cells involves two steps: surface binding on the cell membrane and internalization. ${ }^{48} \mathrm{SPR}$ was performed to detect the interaction between the sensor surface with the receptor and targeting ligand in samples. Figure 4 shows representative sensorgrams of the binding of GE, GEH, or GEH-RGD to integrin $\alpha_{v} \beta_{3}$ on the sensor chip. Both GE and GEH-RGD NPs possess positive charge on their surface (23.7 vs $19.7 \mathrm{mV}$ ), causing a stronger SPR signal. The GEH
NPs, with negative charge $(-11.3 \mathrm{mV})$, show a lower signal in RU. Therefore, the surface charge of NPs also plays an important role in $\alpha_{v} \beta_{3}$ binding. As such, it is not reasonable to ignore or subtract the GE- $\alpha_{\mathrm{v}} \beta_{3}$ signal in current SPR work. GE was modified into GEH and GEH-RGD NPs through coating HA and HA-RGD on the surface. The RU value of GE was set as the base to calculate the relative binding affinity. The binding affinity of GEH and GEH-RGD was about 0.5 -fold and 1.5-fold that of GE, respectively. The result means that HA treatment can reduce binding affinity to $\alpha_{\mathrm{v}} \beta_{3}$, due to the opposite surface charge, but HA-RGD treatment (GEH-RGD) will increase affinity to 1.5-fold that of GE, due to the RGD- $\alpha_{\mathrm{v}} \beta_{3}$ interaction. It was noticed that the affinityincreasing effect from GEH to GEH-RGD was threefold the contribution of the synergistic effect of surface charge and RGD $-\alpha_{\mathrm{v}} \beta_{3}$ interactions. The RGD-doxorubicin (DOX)dendritic poly(L-lysine) (DGL)-GNP delivery system was developed by Guo et al, and their SPR results also showed that the binding proportion of RGD-DOX-DGL-GNP was significantly higher than that of DOX-DGL-GNP (non-RGD grafted NPs). ${ }^{49}$ According to the specific targeting capacity of GEH-RGD to recognize $\alpha_{v} \beta_{3}$, it can be easily taken up by HUVECs (Figure 5), decreasing cell viability to $60 \%$ at low EGCG concentrations (Figure 6, EGCG $20 \mu \mathrm{g} / \mathrm{mL}$, day 3), and then effectively inhibiting HUVEC migration, lasting for a longer period than free EGCG, due to the slow release of EGCG from GEH-RGD (Figure 7).

In this study, GEH-RGD NPs were used as eyedrops and applied twice daily for 7 days in a mouse model of corneal NV. The drug inhibited vascular ingrowth from the limbic to the central cornea (Figure 8), a tendency similar to a previous report showing that double dosing of curcumin NPs can prevent corneal NV. ${ }^{36}$ The vessel number and size obviously decreased when compared with those in mice treated with free EGCG solution. Although the design for GEH-RGD is to target vascular endothelial cells, in vitro targeting was confirmed via HUVEC cells, though in an animal study this is really a very dynamic and complicated condition on the ocular surface. We speculate that electrical attraction might be the first factor to influence NP adhesion on the surface, then the RGD ligand can help the adhesion of NPs at the damaged area of the extracellular matrix with integrin receptors or some area with $\alpha_{\mathrm{v}} \beta_{3}$ receptors to facilitate binding, causing a high number of particles on the surface. This strong interaction can be attributed to the electrical attraction between GEH-RGD with positive charge and cornea/ conjunctiva possessing negative charge (Table 1). With the longer retention time, GEH-RGD causes higher accumulation 
of NPs on the eye, allowing time to search for vascular receptors on vessels for binding. Further studies are warranted to identify the mechanism underlying the inhibitory effects of GEH-RGD NPs used as eyedrops in corneal NV.

\section{Conclusion}

The protocol used to conjugate HA with GRGSPK peptide on GE NPs was developed to prepare antiangiogenic peptide therapeutics for the treatment of corneal NV. The RGD-HA conjugate was successfully synthesized by amide-bond formation between the carboxyl groups of HA and N-terminal amine groups of RGD peptides using EDC/NHS as a coupling reagent. The HA-RGD coating on the GEH-RGD was fabricated to target the $\alpha_{\mathrm{v}} \beta_{3}$ integrin on HUVECs. The average diameter of GEH-RGD was $168.87 \pm 22.5 \mathrm{~nm}$, with an EGCG-loading efficiency up to 95\%. A slow release pattern was observed in these NPs, including GEH-RGD. SPR examination confirmed that GEH-RGD specifically bound to $\alpha_{\mathrm{v}} \beta_{3}$ immobilized on the chip. In vitro cell-viability assay showed that GEH-RGD efficiently targeted and accumulated in HUVECs. HUVEC viability was reduced to $60 \%$ at an EGCG concentration of $20 \mu \mathrm{g} / \mathrm{mL}$ on day 3 of treatment. Furthermore, GEH-RGD NPs significantly inhibited the HUVEC-migration rate to $58 \%$ after 24 hours. Mice with corneal NV treated by eyedrops with GEH-RGD NPs showed less vessel formation in cornea after 7 days treatment. Overall, GEH-RGD NPs were successfully developed as a novel vascular endothelial cell inhibitor. Additionally, GEH-RGD NPs can be used as eyedrop for the treatment of corneal NV in the near future.

\section{Acknowledgment}

This work was supported by grants from an integrated research grant in health and medical sciences from the National Health Research Institute (NHRI), Taiwan (NHRIEX103-10334EI, NHRI-EX104-10334EI, and NHRI-EX10510334EI) awarded to CLT. We also appreciate the support from Ministry of Science and Technology (MOST), Taiwan, under grant number at 105-2918-I-038-001. And, Centre for Eye Research Australia receives operational infrastructure support from the Victorian Government.

\section{Disclosure}

The authors report no conflicts of interest in this work.

\section{References}

1. Menzel-Severing J. Emerging techniques to treat corneal neovascularisation. Eye (Lond). 2012;26:2-12.
2. Huang TL, Hsu SY, Tsai RK, Sheu MM. Etiology of ocular diseases in elderly Amis aborigines in Eastern Taiwan (the Amis Eye Study). Jpn J Ophthalmol. 2010;54:266-271.

3. Bachmann BO, Bock F, Wiegand SJ, et al. Promotion of graft survival by vascular endothelial growth factor: a neutralization after high-risk corneal transplantation. Arch Ophthalmol. 2008;126: 71-77.

4. Azar DT. Corneal angiogenic privilege: angiogenic and antiangiogenic factors in corneal avascularity, vasculogenesis, and wound healing (an American Ophthalmological Society thesis). Trans Am Ophthalmol Soc. 2006;104:264-302.

5. Bock F, König Y, Kruse F, Baier M, Cursiefen C. Bevacizumab (Avastin) eye drops inhibit corneal neovascularization. Graefes Arch Clin Exp Ophthalmol. 2008;246:281-284.

6. Dastjerdi MH, Al-Arfaj KM, Nallasamy N, et al. Topical bevacizumab in the treatment of corneal neovascularization: results of a prospective, open-label, noncomparative study. Arch Ophthalmol. 2009;127: 381-389.

7. Davis J, Gilger B, Robinson M. Novel approaches to ocular drug delivery. Curr Opin Mol Ther. 2004;6:195-205.

8. Binstock EE, Domb AJ. Nanoparticles in ocular drug delivery. In: Domb AJ, Tabata Y, Kumar MN, Farber S, editors. Nanoparticles for Pharmaceutical Applications. Valencia (CA): American Scientific Publishers; 2007:367-376.

9. Davies NM. Biopharmaceutical considerations in topical ocular drug delivery. Clin Exp Pharmacol Physiol. 2000;27:558-562.

10. Nagarwal RC, Kant S, Singh PN, Maiti P, Pandit JK. Polymeric nanoparticulate system: a potential approach for ocular drug delivery. J Control Release. 2009;136:2-13.

11. Rodriguez SK, Guo W, Liu L, Band MA, Paulson EK, Meydani M. Green tea catechin, epigallocatechin-3-gallate, inhibits vascular endothelial growth factor angiogenic signaling by disrupting the formation of a receptor complex. Int $J$ Cancer. 2006;118: $1635-1644$.

12. Kojima-Yuasa A, Hua JJ, Kennedy DO, Matsui-Yuasa I. Green tea extract inhibits angiogenesis of human umbilical vein endothelial cells through reduction of expression of VEGF receptors. Life Sci. 2003;73: 1299-1313.

13. Koh CH, Lee HS, Chung SK. Effect of topical epigallocatechin gallate on corneal neovascularization in rabbits. Cornea. 2014;33:527-532.

14. Donà $\mathrm{M}$, Dell'Aica, Calabrese $\mathrm{F}$, et al. Neutrophil restraint by green tea: inhibition of inflammation, associated angiogenesis, and pulmonary fibrosis. J Immunol. 2003;170:4335-4341.

15. Cavet ME, Harrington KL, Vollmer TR, Ward KW, Zhang JZ. Antiinflammatory and anti-oxidative effects of the green tea polyphenol epigallocatechin gallate in human corneal epithelial cells. Mol Vis. 2011; $17: 533-542$

16. Friedlander $M$, Theesfeld CL, Sugita $M$, et al. Involvement of integrins $\alpha_{v} \beta_{3}$ and $\alpha_{v} \beta_{5}$ in ocular neovascular diseases. Proc Natl Acad Sci US A. 1996;93:9764-9769.

17. Danhier F, Breton AL, Préat V. RGD-based strategies to target $\alpha_{4} \beta_{3}$ integrin in cancer therapy and diagnosis. Mol Pharm. 2012;9:2961-2973.

18. Tian H, Lin L, Chen J, Chen X, Park TG, Maruyama A. RGD targeting hyaluronic acid coating system for PEI-PBLG polycation gene carriers J Control Release. 2011;155:47-53.

19. Chen YC, Yu SH, Tsa GJ, Tang DW, Mi FL, Peng YP. Novel technology for the preparation of self-assembled catechin/gelatin nanoparticles and their characterization. J Agric Food Chem. 2010;58:6728-6734.

20. Shutava TG, Balkundi SS, Lvov YM. (-)-Epigallocatechin gallate/ gelatin layer-by-layer assembled films and microcapsules. $J$ Colloid Interface Sci. 2009;330:276-283.

21. Tseng CL, Lin FH. Preparation of gelatin nanoparticles with EGFR selection ability via biotinylated-EGF conjugation for lung cancer targeting. Biomed Eng (Singapore). 2008;20:161-169.

22. Chan EC, van Wijngaarden $P$, Chan E, et al. NADPH oxidase 2 plays a role in experimental corneal neovascularization. Clin Sci. 2016;130: 683-696. 
23. Oh EJ, Park K, Choi JS, Joo CK, Hahn SK. Synthesis, characterization, and preliminary assessment of anti-Flt1 peptide-hyaluronate conjugate for the treatment of corneal neovascularization. Biomaterials. 2009; 30:6026-6034.

24. Huerta-Angeles G, Bobek M, Př́́kopová E, Smejkalová D, Velebný V. Novel synthetic method for the preparation of amphiphilic hyaluronan by means of aliphatic aromatic anhydrides. Carbohydr Polym. 2014;111: 883-891.

25. Wishart DS, Knox C, Guo AC, et al. DrugBank: a comprehensive resource for in silico drug discovery and exploration. Nucleic Acids Res. 2006;1:D668-D672.

26. Ge H, Tian P, Guan L, et al. A C-terminal fragment BIGH3 protein with an RGDRGD motif inhibits corneal neovascularization in vitro and in vivo. Exp Eye Res. 2013;112:10-20.

27. Ono M. Molecular links between tumor angiogenesis and inflammation: inflammatory stimuli of macrophages and cancer cells as targets for therapeutic strategy. Cancer Sci. 2008;99:1501-1506.

28. Sánchez-Huerta V, Gutiérrez-Sánchez L, Flores-Estrada J. (-)-Epigallocatechin 3-gallate (EGCG) at the ocular surface inhibits corneal neovascularization. Med Hypotheses. 2011;76:311-313.

29. Gillespie K, Kodani I, Dickinson D, et al. Effects of oral consumption of the green tea polyphenol EGCG in a murine model for human Sjögren's syndrome, an autoimmune disease. Life Sci. 2008;83:581-588.

30. Zhong ZF, Hoi PM, Wu GS, et al. Anti-angiogenic effect of furanodiene on HUVECs in vitro and on zebrafish in vivo. J Ethnopharmacol. 2012;141:721-727.

31. Li Z, Gu L. Fabrication of self-assembled (-)-epigallocatechin gallate (EGCG) ovalbumin-dextran conjugate nanoparticles and their transport across monolayers of human intestinal epithelial Caco-2 cells. J Agric Food Chem. 2014;62:1301-1309.

32. Diebold Y, Jarrín M, Sáez V, et al. Ocular drug delivery by liposomechitosan nanoparticle complexes (LCS-NP). Biomaterials. 2007;28: $1553-1564$.

33. Bourges JL, Gautier SE, Delie F, et al. Ocular drug delivery targeting the retina and retinal pigment epithelium using polylactide nanoparticles. Invest Ophthalmol Vis Sci. 2003;44:3562-3569.

34. de la Fuente M, Seijo B, Alonso MJ. Novel hyaluronic acid-chitosan nanoparticles for ocular gene therapy. Invest Ophthalmol Vis Sci. 2008; 49:2016-2024.

35. Başaran E, Demirel M, Sirmagül B, Yazan Y. Cyclosporine-A incorporated cationic solid lipid nanoparticles for ocular delivery. J Microencapsul. 2010;27:37-47.

36. Pradhan N, Guha R, Chowdhury S, Nandi S, Konar A, Hazra S. Curcumin nanoparticles inhibit corneal neovascularization. $J \mathrm{Mol}$ Med (Berl). 2015;93:1095-1106.
37. Qazi Y, Stagg B, Singh N, et al. Nanoparticle-mediated delivery of shRNA.VEGF-A plasmids regresses corneal neovascularization. Invest Ophthalmol Vis Sci. 2012;53:2837-2844.

38. Tseng CL, Chen KH, Su WY, Lee YH, Wu CC, Lin FH. Cationic gelatin nanoparticles for drug delivery to the ocular surface: in vitro and in vivo evaluation. J Nanomater. 2013;2013:238351.

39. Bernstein-Levi O, Ochbaum G, Bitton R. The effect of covalently linked RGD peptide on the conformation of polysaccharides in aqueous solutions. Colloids Surf B Biointerfaces. 2016;137:214-220.

40. Kanakis CD, Hasni I, Bourassa P, Tarantilis PA, Polissiou MG, TajmirRiahi HA. Milk $\beta$-lactoglobulin complexes with tea polyphenols. Food Chem. 2011;127:1046-1055.

41. Prokop A, Davidson JM. Nanovehicular intracellular delivery systems. Pharm Sci. 2008;97:3518-3590.

42. Li Z, Gu L. Fabrication of self-assembled (-)-epigallocatechin gallate (EGCG) ovalbumin dextran conjugate nanoparticles and their transport across monolayers of human intestinal epithelial Caco 2 cells. J Agric Food Chem. 2014;62:1301-1309.

43. Zhou H, Sun X, Zhang L, Zhang P, Li J, Liu YN. Fabrication of biopolymeric complex coacervation core micelles for efficient tea polyphenol delivery via a green process. Langmuir. 2012;28:14553-14561.

44. Honda S, Nagai T, Negi A. Anti-angiogenic effects of non-peptide integrin $\alpha_{v} \beta_{3}$ specific antagonist on laser-induced choroidal neovascularization in mice. Graefes Arch Clin Exp Ophthalmol. 2009;247:515-522.

45. Chang JH, Garg NK, Lunde E, Han KY, Jain S, Azar DT. Corneal neovascularization: an anti-VEGF therapy review. Surv Ophthalmol. 2012;57:415-429.

46. Tiger CF, Fougerousse F, Grundstrom G, Velling T, Gullberg D. $\alpha_{11} \beta_{1}$ Integrin is a receptor for interstitial collagens involved in cell migration and collagen reorganization on mesenchymal nonmuscle cells. Dev Biol. 2001;237:116-129.

47. Stepp MA. Corneal integrins and their functions. Exp Eye Res. 2006; $83: 3-15$.

48. Guo Z, He B, Jin H, et al. Targeting efficiency of RGD-modified nanocarriers with different ligand intervals in response to integrin $\alpha_{\mathrm{v}} \beta_{3}$ clustering. Biomaterials. 2014;35:6106-6117.

49. Hu G, Zhang H, Zhang L, Ruan S, He Q, Gao H. Integrin-mediated active tumor targeting and tumor microenvironment response dendrimer-gelatin nanoparticles for drug delivery and tumor treatment. Int J Pharm. 2015;496:1057-1068.
International Journal of Nanomedicine

\section{Publish your work in this journal}

The International Journal of Nanomedicine is an international, peerreviewed journal focusing on the application of nanotechnology in diagnostics, therapeutics, and drug delivery systems throughout the biomedical field. This journal is indexed on PubMed Central, MedLine, CAS, SciSearch ${ }^{\circledR}$, Current Contents ${ }^{\circledR} /$ Clinical Medicine,

\section{Dovepress}

Journal Citation Reports/Science Edition, EMBase, Scopus and the Elsevier Bibliographic databases. The manuscript management system is completely online and includes a very quick and fair peer-review system, which is all easy to use. Visit http://www.dovepress.com/ testimonials.php to read real quotes from published authors. 